\title{
Warime piaroa: cuatro performances en un rito
}

\author{
Warime Piaroa: Four Performances in One Rite
}

DOI 10.22380/2539472X.803

\author{
Alexander Mansutti Rodríguez \\ Universidad Nacional de Educación, Ecuador
}

\begin{abstract}
RESUMEN
El Warime es una modalidad de yuruparí que festejan los piaroas de la Orinoquia venezolana y colombiana. Durante su desarrollo se generan cuatro escenarios de comunicación musicalizada, dos de diálogos y dos de monólogos. Coinciden los diálogos profanos en medio de monólogos sagrados, los cantos sagrados de estructura rígida respondidos por cantos profanos de contenidos personalizados. Concluimos que los cantos profanos en respuesta a los cantos sagrados son la humanización de la relación, que los encuentros dialogados son posibles allí donde hay equidad sin peligro, mientras que los monólogos se dan donde la comunicación está verticalmente jerarquizada.
\end{abstract}

Palabras claves: Orinoquia, Yuruparí, Warime, piaroa.

\begin{abstract}
Warime is a form of yurupari celebrated by the Piaroas of the Venezuelan and Colombian Orinoquia. During its performance, there are four scenarios of musical communication, two dialogues and two monologues. We observe that the profane dialogues coincide in the midst of sacred monologues, the sacred songs of rigid structure are answered by profane chants of personalized contents. We conclude that the profane songs in response to the sacred songs are the humanization of the relationship and that the dialogue meetings are possible where there is equity without danger, whereas the monologues occur where communication is highly hierarchized.
\end{abstract}

Keywords: Orinoquia, Yuruparí, Warime, Piaroa.

Doctor en Antropología y Etnología de la Escuela de Estudios Superiores en Ciencias Sociales (Ehess) de París. Docente investigador de Educación Intercultural Bilingüe de la Universidad Nacional de Educación (UNAE) de Ecuador. alexander.mansutti@unae.edu.ec / https://orcid. org/0000-0002-6681-3667 


\section{Introducción ${ }^{1}$}

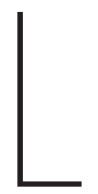

os piaroas, también conocidos como uwotjuja y dearuwa en la literatura, hablan una lengua de la familia lingüística sáliva. Habitan sectores del medio y alto Orinoco en Venezuela y Colombia (figura 1). En la abundante literatura etnográfica ${ }^{2}$ son conocidos por su carácter apacible, el control que ejercen sobre la violencia física, el desarrollo chamánico y el efecto jerarquizador de la fiesta Warime sobre una sociedad usualmente igualitaria.

El Warime es una modalidad de los yuruparí ${ }^{3}$ que se practican o que fueron practicados por las sociedades tukanas, arawakas e independientes del noroeste de la cuenca amazónica y del sur del Orinoco. De hecho, los cronistas de la colonización en la Orinoquia nos indican que, cuando estuvieron allí durante los siglos XVIII y XIX, otras modalidades de yuruparí se dieron entre sociedades de los llanos del Meta y del suroeste de la actual Venezuela (Gilij 1965; Gumilla 1988; Humboldt 1991, IV). Aunque algunas modalidades de yuruparí desaparecieron con las sociedades que las practicaban, rasgos que las caracterizaban pudieron pasar a sus descendientes actuales gracias al intenso proceso de sincretismo cultural que se dio entre los grupos que lograron sobrevivir y los restos de aquellos que ya no están (Mansutti y Bonneuil 1994-1996). De allí la diversidad de nombres y prácticas dados por los piaroas a los warimes, en el entendido de que ellos son miembros de una de esas sociedades que hereda y tiende a sintetizar, con los

1 Agradezco a los piaroas, al financiamiento del Instituto Caribe de Antropología y Sociología (ICAS), a la Fundación La Salle de Ciencias Naturales (Flasa), al CIAG-UNEG y a la UNAE por la oportunidad de reflexionar desde la educación intercultural bilingüe sobre los datos recogidos; a la doctora Patricia Pauta por asesorarme en la caracterización de las expresiones musicales piaroa, y a los árbitros por sus sabios consejos.

2 La bibliografía sobre los piaroas es abundante. Algunos de los trabajos más importantes son: Anduze (1974); Boglar (1971); Mansutti (1990); Monod (1970, 1987); Oldham (1996); Overing (1975); Zent (1992).

3 El yuruparí es un nombre genérico, polisémico según Reichel-Dolmatoff (1996), que alude a un ritual promovido por una sociedad secreta de hombres que se caracteriza por la presencia de instrumentos sagrados, por lo general aerófonos, que son metáfora de las voces de seres extraordinarios y que no pueden ser vistos por las mujeres ni por los no iniciados. Es propio del noroeste amazónico, entre el río Sipapo al norte, en Venezuela, y el Caquetá al sur, en Colombia. Su práctica durante el siglo XX ha sido reportada, con variantes, entre los puinavis, los geral, los tukunas, los desanas, los pira-tapuya, los tukanos, los uananos, los cubeos, los makunas, los barasanas, los baras, los piaroas y los wirös (Arnhem 1981; Goldman 1948; González 1986; Hill 1993; Hugh-Jones 1979, 1996; Jackson 1983; Lowie 1948; Mansutti 2006; Metraux 1982; Pérez 1988; Reichel-Dolmatoff 1973, 1996; Vidal 2002; Wilbert 1966; Wright 1998, 2002). 
Figura 1. Ubicación actual de los piaroas en Venezuela y Colombia

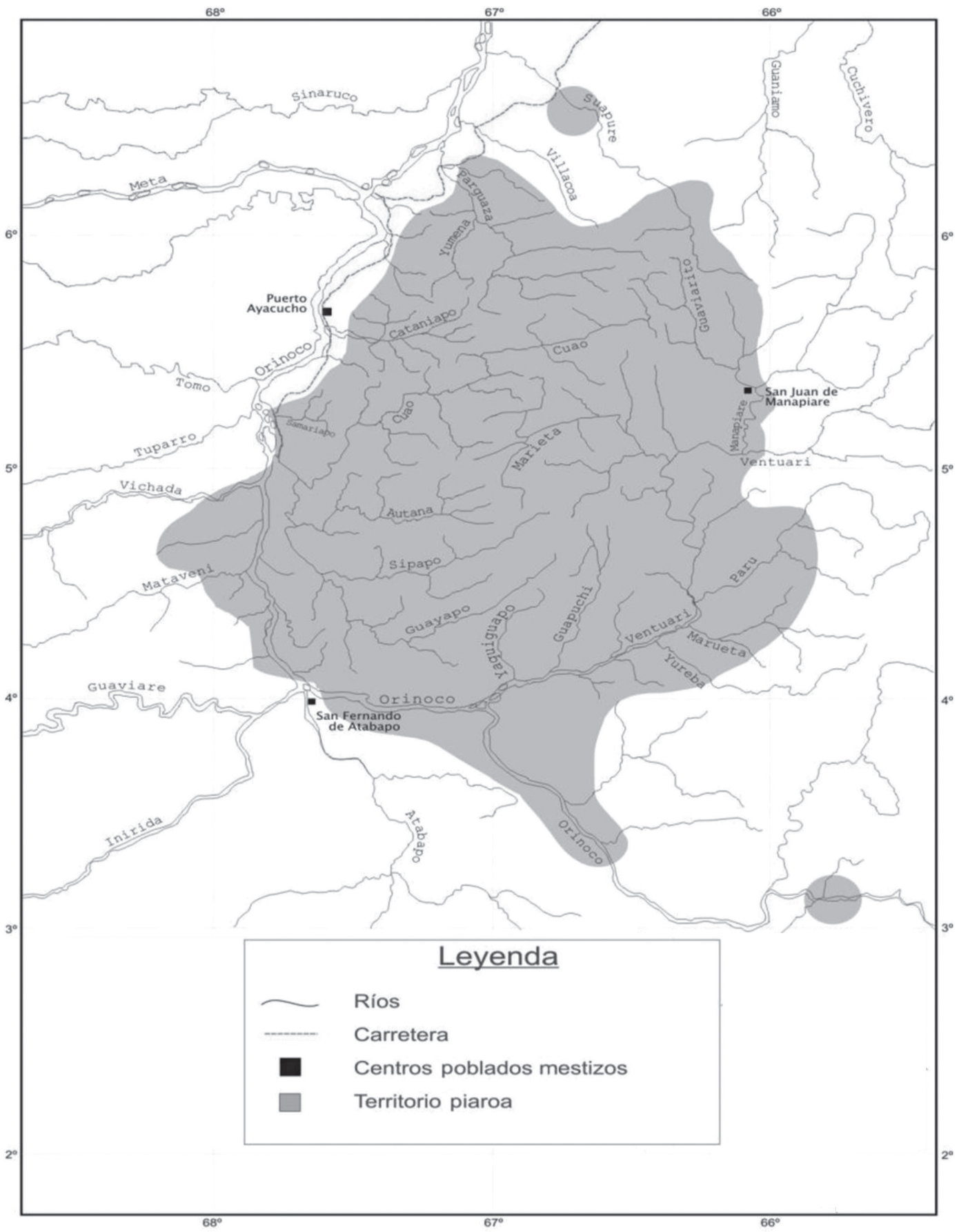

Fuente: mapa elaborado por Erik Jose Lares Belmontes. 
suyos propios, elementos de las múltiples modalidades de yuruparís arawakos y sálivas que se daban en su entorno.

El Warime es un ritual complejo realizado por los piaroas y los wirös del Orinoco. Puede durar varios meses durante el periodo de lluvias que se inicia en abril, dependiendo de la abundancia de la comida que ha de servirse tanto a los invitados piaroas como a los no humanos. A ella asisten los miembros chawaruwa tuku (amigos cercanos con quienes bebo) de las comunidades vecinas y aliados. Se caracteriza por la presencia de seres enmascarados de pecaríes, de mono blanco, de murciélago y de Reyó, el humanoide dueño de los animales de presa, y de un grupo de voces musicales cuyos emisores no pueden ser vistos por las mujeres ni por los no iniciados. Entre las voces se destacan Worá (la dueña de la agricultura), Yajó (el tucán, dueño de las frutas), Chuvó (la voz del demiurgo Wajari), Buoisa (el Viejo) e Imú (el mono aullador). Además, estará presente Ojuo'daa, dueño de los animales del río, en forma de canoa de fermentación de la cerveza de yuca (Manihot esculenta C.). Durante su desarrollo se dan intercambios comerciales, se arreglan matrimonios, los chamanes rezan juntos y se producen ritos de transición (Mansutti 2006)

Hemos descrito el desarrollo completo de la fiesta (Mansutti 2003, 2006, 2012), los instrumentos musicales utilizados (Mansutti 2011a) y las máscaras y su función (Mansutti 2011b). Otros autores como Terry Agerkoop (1983), Lajos Boglar (1976, 1999), Allain Gheerbrant (1953), Alfred Metraux (1982), Jean Monod (1972) y el marqués de Wavrin (1948) han desarrollado aspectos de la fiesta. En este artículo nos detendremos en los espacios de comunicación musical ${ }^{4}$ para entender el papel que desempeñan en el entramado de una fiesta compleja en la que se celebra la relación que existe entre todos los actores culturales ${ }^{5}$, humanos y no humanos, que garantizan la fecundidad del mundo piaroa.

4 Un espacio de comunicación musical es un conjunto organizado de sonidos que se da en un entorno determinado a partir de mensajes codificados por formas preestablecidas. Todo espacio de comunicación musical genera un paisaje musical que impresiona los sentidos. Las acciones musicales se llenan de significación a partir de la relación particular que existe entre el emisor y el receptor: si ambos comparten el mismo código, la intención comunicativa del emisor será cercana a la interpretación del receptor. Si, por el contrario, emisores y receptores pertenecen a culturas diferentes, lo que el emisor querrá comunicar será interpretado por el escucha desde espacios de significación propios y diferentes. Cuando la relación ocurre en un ambiente chamánico sirve para construir y transformar lazos sociales (Hill y Chaumeil 2011). Se trata de mecanismos de comunicación no verbales que impactan y atraviesan los otros espacios relacionales de la sociedad. Entendemos que la ritualidad del Warime, densamente poblada de voces, ritmos y melodías, es un espacio de comunicación musical en el que se dan múltiples interrelaciones cuya significación depende de los actores sociales que los establecen y del código que les da sentido.

5 Se entiende por actores culturales a todos aquellos entes que disfrutan, como el ser humano, de las artes de la palabra creativa y del chamanismo. Se trata de seres que, aunque convivan o no con los humanos, comparten con ellos la cultura. 


\section{La comunicación y los diálogos}

La etnomusicología que investiga las expresiones culturales de los pueblos originarios de América del Sur, donde están presentes la música, el canto y el baile, abre nuevos horizontes de reflexión comparada gracias a la reciente publicación de libros temáticos que empujan hacia un replanteamiento del papel de las artes, la música y sus lenguajes en estas sociedades (Brabec de Mori, Lewy y García 2017; Goulard y Karadimas 2011; Hill y Chaumeil 2011).

En el caso piaroa que nos ocupa, encontramos una sociedad poco prolífica en instrumentos y géneros musicales cuyos miembros, especialmente los hombres, se caracterizan por el severo autocontrol de las emociones - condición indispensable de autoridad y prestigio-. De hecho, cuando los hombres y mujeres no son capaces de autocontrolarse, sobrevienen tragedias, como lo enseñan los mitos asociados con la adquisición del perturbador chamanismo de agresión por el demiurgo creador Wajari y la creación de las enfermedades y la muerte. En efecto, Cheheru, la hermana del demiurgo creador Wajari, se enamora de Chuvó, la voz musical de su hermano, sin saber que, al tratar de apropiársela, promueve un incesto que culmina con la destrucción del ser que genera la voz. Ante la grave transgresión, Wajari decide vengarse creando las enfermedades y con ellas causa la muerte a sus sobrinos, los hijos de Cheheru.

El ideal de autocontrol piaroa es asexuado y nos remite a una persona, hombre o mujer, que no se deja dominar por sus emociones. A los hombres se les impone esta virtud con mayor firmeza. Las exigencias son más flexibles con las mujeres y los niños, pues se considera que tienen dificultades para controlar sus emociones por su mayor impulsividad.

La mitología baniwa de las flautas sagradas asociadas con su yuruparí (Wright 1998, 161) nos cuenta que los hombres debieron despojar de ellas a las mujeres, quienes se las habían apropiado porque, enamoradas de sus voces, descuidaban a sus hijos y familia. Por ello, los hombres debieron expropiarlas y convertirlas en secretas para las mujeres. A ellas solo les quedó el disfrute de la escucha mientras que la ejecución de las voces musicales quedó exclusivamente en las manos de los hombres. Entre los piaroas, el único mito que explica la causa de la exclusión de las mujeres de la vista de estas voces musicales sagradas por su limitado autocontrol es el del origen de las enfermedades mediante las cuales Wajari castiga a su hermana Cheheru.

El principio de vida piaroa es el hálito o yuwä. El hálito convertido en soplo o en palabra es el más poderoso instrumento transformador del mundo 
piaroa $^{6}$. De hecho, entre los piaroas hay dos clases de chamanes: los rezadores o meyeruwa y los sopladores o yuwäwäruwa. El yuwäwäruwa es el más peligroso, pues con el poder de su soplo es capaz de destruir realidades. Ello demuestra que el hálito es fuerza que puede ser transformada en arma mortal. En contraste, el chamán creador, el meyeruwa, es quien canta sus oraciones (meyé) para hacer prolífico el mundo.

El hálito hecho soplo es poder bruto, es poder peligroso, difícil de controlar. En contraste, el hálito hecho palabra y hecho música es poder cultural, más sofisticado y por ello también más controlado. Con el soplo se mata, con la palabra se crea, aunque también se puede matar. Hacer música cantando o con aerófonos es cultivar el hálito por la modulación de su poder en palabras hechas oración (meyé) o por la transformación de la fuerza del aliento en acordes. Así, al poder natural del soplo se lo domestica. La mitología de los tiempos de la creación comienza diciéndonos que Buoka, el mayor y primero de los hermanos demiurgos de la creación, nace “como un corazón de la palabra del viento”.

Para nuestro análisis tomaremos cuatro escenarios de comunicación musical que ocurren en una misma fiesta, pero en diferentes momentos de ella ${ }^{7}$. Solo trabajaremos con estos cuatro momentos de la fiesta Warime. El primero es un monólogo. En los otros tres hay al menos dos interlocutores, aunque en algunos casos el diálogo pueda convertirse en polílogo. Los monólogos de Worá, la más importante de las voces musicales, aparecen desde los preparativos de la fiesta para marcar momentos importantes. En el segundo momento tenemos el diálogo que se establece entre los warimes enmascarados, cuyos cantos míticos al llegar a la maloca son acompañados y respondidos por una mujer en representación del dominio doméstico. El tercero es un polílogo que adquiere la forma de una orquesta de voces, cada una de las cuales ejecuta sus propios movimientos y transmite su mensaje, tanto a los compañeros de orquesta como a los que están recluidos en la maloca. El cuarto es el diálogo que se establece entre los libidinosos buoisas (el Viejo), quienes hablan desde el entorno cercano de la maloca con una o varias mujeres que se encuentran en su interior; ambos actores pueden escucharse y dialogar, pero no verse. Nuestra hipótesis es que cada escenario

6 El primer capítulo de mi tesis doctoral desarrolla la concepción del poder del soplo y la palabra en el mundo piaroa (Mansutti 2002). Recientemente, De la Hoz (2015) también publicó un ensayo sobre el mismo tema.

7 Es necesario aclarar que en este trabajo no trataremos la comunicación que se da en los actos chamánicos convencionales de curación de enfermedades, chamanismo de agresión, limpieza de los alimentos y fecundidad del entorno, que se realizan en cualquier momento de la vida cotidiana y en los que hay intervención musical con el ritmo que impone la maraca chamánica. Estos requerirían otro tratamiento. 
tiene sus propios actores y transmite sus propios mensajes. No se trata, entonces, de un solo escenario regido por un protocolo rígido, sino de múltiples espacios donde se expresa la complejidad de las relaciones que establecen los piaroas con sus ancestros y con el mundo cultural no humano.

\section{Primer escenario: la llegada y los anuncios de Worá}

Worá es un personaje ambiguo. Ella funge de madre de todas las voces melódicas de los seres extraordinarios que asisten a la fiesta. También le dicen Woraju, con el sufijo ju, con el que reafirman su condición femenina. Jean Monod (1987, 34) afirma que ella es la misma Cheheru, la única hermana menor de los demiurgos Buoka y Wajari, quien crea la agricultura y los rezos contra las enfermedades. Cheheru es la única hermana entre los demiurgos creadores y dentro de la concepción piaroa se trata de un personaje que, al controlar el mundo agrícola y el de los medicamentos, es culturalmente avanzada frente a sus hermanos que controlan el mundo del chamanismo destructivo.

Asociada al nombre de Worá tenemos a la piedra worájuwa (piedra de la Worá), que se encuentra en las siembras y a la que se considera piedra madre de los cultivos, un papel similar al de las poitjiana, que son las piedras madres de los peces. A ambas se les reza, a la una para liberar los espíritus de los peces y a la otra para liberar los espíritus de las frutas silvestres y cultivos que se encuentran en su interior. Según nuestros informantes ${ }^{8}$, su ronca voz al cantar — “juu juu juu"- representa el rugido del jaguar, en lo que coinciden con los informantes de Agerkoop $(1983,42)$, un etnomusicólogo de Surinam que trabajó con los piaroas en la década de los setenta.

El discurso musical de Worá es el resultado de dos flautas unitonales introducidas alternadamente en una caja de resonancia constituida por una botija de cerámica a la que los dos ejecutantes agarran con una mano, cada uno por su lado, mientras con la otra mano sostienen cada uno su flauta. Worá es la más importante de las voces musicales; como dueña de la agricultura, es la jefa. Preside todos los actos importantes, tanto de la preparación como de la realización de la fiesta. Su voz se escucha cuando los hombres terminan de construir su casa secreta o ruwode, cuando en el mismo ruwode los hombres terminan de ensamblar

8 Trabajamos con los piaroas desde 1983. Los datos que se presentan aquí han sido recogidos de diferentes fuentes, hombres warimeruwa (dueño de Warime), yuwäwäruwa (dueño de los soplos) y meyeruwas (dueño de los rezos) y por mujeres sariruwa (dueña de la cerveza de yuca). Todos ellos eran adultos mayores y partícipes de la ejecución ritual. Los datos más densos me los dio el capitán Bolívar, quien nos permitió hacer la etnografía de su fiesta y filmarla, pero nuestros cuadernos de campo están llenos de otras referencias. 
o refaccionar cada una de las máscaras de pecarí (Tayacu pecari), de murciélago (Desmodus rotundus) y de mono blanco (Cebus olivaceus). También canta cuando terminan de obtener los brotes de hojas de Mauritia flexuosa de donde sacarán la fibra para hacer las cortinas de las máscaras, cuando han arrancado la corteza de árbol con la que confeccionarán el traje de Märä Reyó, cuando han talado el árbol de madera blanda ${ }^{9}$ e, intermitentemente, mientras horadan su fuste para hacer la canoa de fermentación. Luego suena cuando visita los alrededores de la maloca durante la noche, junto con la orquesta de voces. Worá se hace omnipresente en todos los momentos importantes de la fiesta.

Worá es el personaje más importante de la fiesta. Es una voz fuerte y potente, rítmica y disciplinada. En la maloca, aquellos que solo la escuchan imaginan la expresión rítmica de un solo ser que manda y se impone en la orquesta del Warime. En estas circunstancias, ella no establece diálogos con los humanos, simplemente comunica su presencia y el éxito de los preparativos.

Los escenarios donde aparece son múltiples. En el bosque, cuando los hombres y jóvenes iniciados recolectan materiales para la fiesta, su voz es entonada frente a todos los presentes, para luego consumir yopo a fin de facilitar el acceso al mundo invisible de los seres extraordinarios. En las cercanías de la maloca, su presencia obliga al enclaustramiento de las mujeres y los niños no iniciados. Por eso aleja a los no iniciados y acerca a los iniciados, pero a todos los convoca. Su presencia, sola o acompañada, oscila entre espacios abiertos y espacios restringidos, pero en todos los casos su voz autoriza y celebra los trabajos que hacen posible el Warime.

\section{Segundo escenario: el diálogo de la mujer y los warimes}

El núcleo central de la fiesta es la visita de los warimes a la maloca colectiva, hombres enmascarados de pecaríes que recrean y actualizan el mito de creación de la fiesta celebrada por el demiurgo Wajari a su suegro Kuemoi, con la ayuda de su hermana Cheheru. Los personajes principales de la escena se ubican alrededor del frente de la entrada de la maloca: allí, tres pecaríes enmascarados propios de la modalidad de Imé Warime $^{10}$ se alinean frente a una mujer, que representa el dominio femenino de la maloca. El enmascarado del medio representa a Wajari,

9 Generalmente, de Ceiba pentandra.

10 En el Wirö Warime son cinco los enmascarados. 
Figura 2. 0juo'daa, el dueño de las aguas, quien, transformado en canoa de fermentación, presta su vientre para depositar el sari que se consumirá en la fiesta

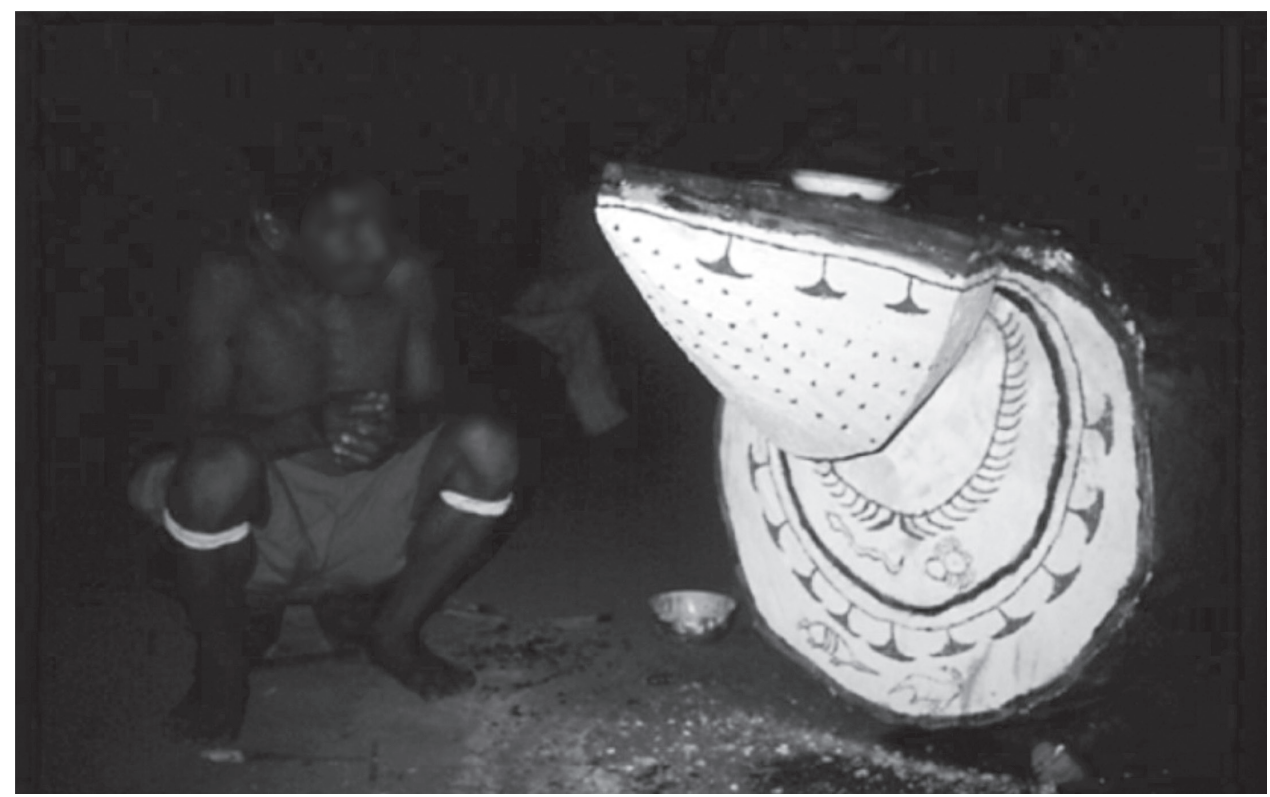

Fuente: fotografía de J. Chiappino.

el más importante de los demiurgos, aquel que se hizo cargo de materializar el mundo soñado por Anamain ${ }^{11}$, reproduciendo lo ocurrido en aquella primera fiesta ofrecida al suegro caníbal en su maloca, en el corazón de la montaña de Pureido. Al frente de los enmascarados, pero atrás de la mujer que les responde, se encuentra Ojuo'daa, (figura 2), el dueño de los animales del agua, quien mantiene en su vientre la cerveza en fermentación de yuca. Alrededor de ellos, están todos los asistentes, con mujeres sirviendo cerveza de yuca (sari) a los warimes y algunos de los hombres arreglando constantemente a los enmascarados para evitar que los no iniciados les vean la cara.

La visita de Wajari y sus compañeros ocurre varias veces durante el día. Cada vez que los pecaríes enmascarados traspasan la entrada a la maloca son recibidos por una mujer que dispone una estera seca de hojas de palma cucurito (Attalea maripa) en el piso de tierra húmeda por los restos de cerveza de yuca, justo para que los warimes de pies desnudos no se los mojen. Se trata de un escenario - el Ime Warime- en el que tres báquiros, venidos de los tiempos

11 Anamain es la fuerza de la luz, es quien sueña el mundo que ha de ser creado por el demiurgo Wajari. 
Figura 3. La mujer responde a los warimes y cuenta su historia

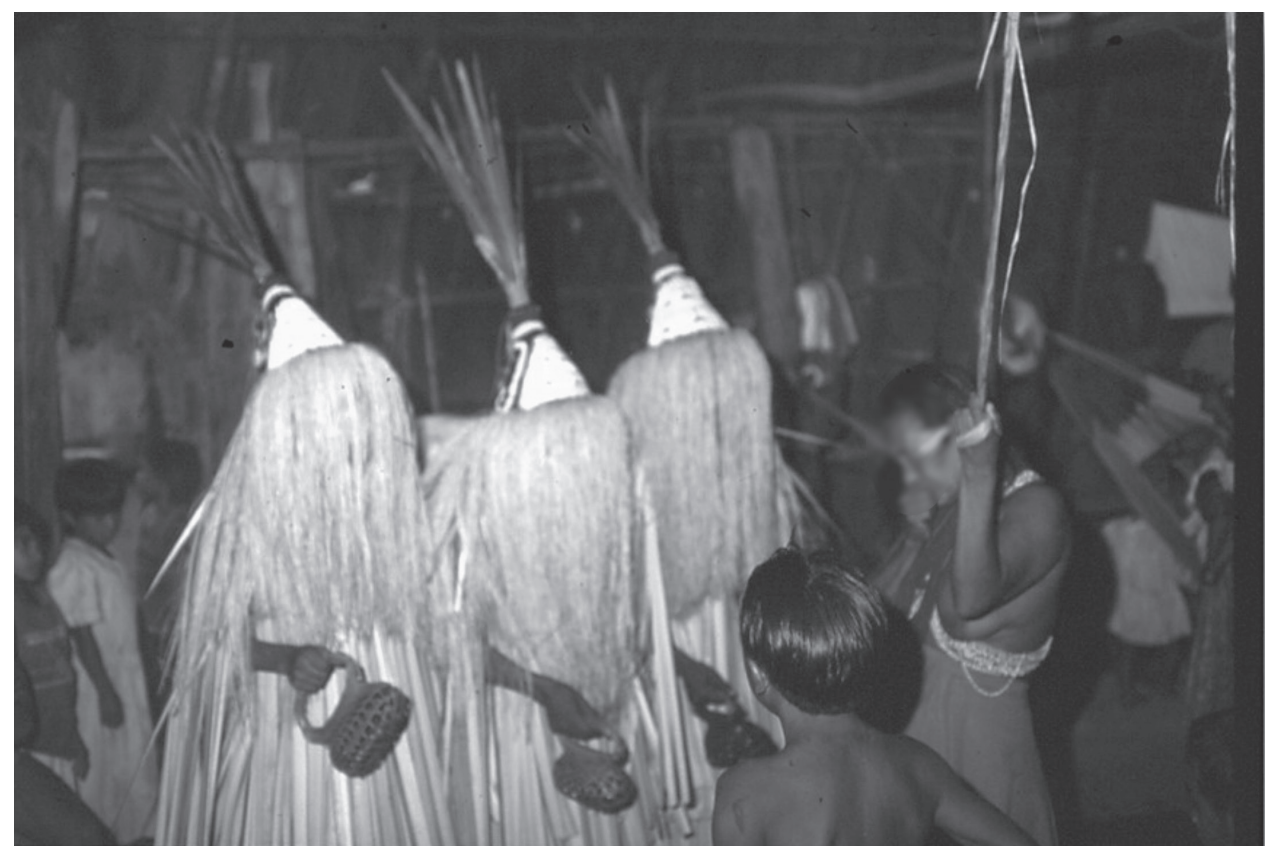

Fuente: fotografía de J. Chiappino.

ancestrales, cuando el mundo se materializaba, son recibidos por una mujer contemporánea, líder y dueña del espacio doméstico, quien brindará a los recién llegados la cerveza de yuca que reposa en el vientre de Ojuo’daa, el mítico ser que reina en las aguas de los ríos y sobre sus habitantes.

El canto de los warimes se inicia al entrar la piara de pecaríes a la maloca en el marco de una rítmica, en fórmulas continuas, producida por el entrechoque en los sonajeros wiwitö rediyu ${ }^{12}$ de las semillas con las que se llenan. Este canto es interpretado por el warime principal ubicado en el centro del grupo quien, en un lenguaje sagrado incomprensible para los no iniciados, cuenta la historia de su origen en los tiempos míticos. Esta interpretación es acompañada por la mujer anfitriona que utiliza intermitentemente modulaciones cortas y repetitivas con efecto nasal. Con ello, la mujer genera la polirritmia con los sonajeros ejecutados por los warimes masculinos.

12 La caja de resonancia de los sonajeros del Warime se elabora con fibra vegetal, a manera de cesta de entramado abierto. El sonido es producido por el entrechoque de semillas triangulares de superficie dura que se encuentran adentro. 
Finalizado el canto de los warimes, entra en escena la respuesta femenina. La mujer canta su historia, la suya y la de su familia, mientras los warimes acompañan ejecutando los sonajeros. Su discurso informa sobre la vida y el perfil de ella, quien los recibe, de quien les da de beber la cerveza que sale del vientre de Ojuo'daa, y de quien los invita a comer. El discurso femenino es el de la retórica del mundo visible, del mundo material, pero en el ámbito de los dominios femeninos.

En estos escenarios se produce un diálogo entre dominios de género: ambos son discursos de origen, como los mirray ${ }^{13}$ típicos del Orinoco (Del Rey Fajardo 2010, 5). Por una parte, un mirray desde el dominio masculino caracterizado por la presentación contemporánea de hechos míticos de contenido chamánico que cuentan el origen del Warime y, con él, de los personajes enmascarados que llegan a la fiesta; por otra parte, del lado femenino, el discurso de los mirray que recuenta el origen material de la mujer, quiénes fueron sus padres y cómo llegó hasta donde está. Uno es un dominio chamánico, el del control de la comunicación con y desde seres extraordinarios, mientras que el otro es el doméstico. Lo que se dicen el warime principal y la mujer subraya las diferencias entre los mundos femenino y masculino; diferencias que no buscan resolver, sino permitir establecer puentes entre ellos, cada uno desde su propio dominio.

Se trata, por tanto, de un diálogo de temas complementarios. El texto de los warimes alude a su origen mítico y al origen de la fiesta que, con su presencia, se reactualiza. El texto de la mujer alude a su origen familiar, terrenal y contemporáneo que, en contacto con los warimes, se hace historia. En estos cantos, historia y mito se hacen historia ambos.

\section{Tercer escenario: el ensamble de seres extraordinarios}

La maloca, de base redonda y techo de hojas de palma que llega hasta el piso, se encuentra siempre en el medio de un terreno limpio de vegetación. Cerca de ella se levanta una pequeña "casa de hombres” o ruwode, cuyo acceso está prohibido a las mujeres y los niños no iniciados. Allí entran y salen hombres y de su interior

13 En el mundo orinoquense del contacto y de la colonización, los mirray eran discursos rituales que les permitían a los visitantes informar a sus anfitriones su origen, perfil y las vicisitudes por las que habían pasado para llegar o estar en el sitio. Funcionaban como preámbulo del establecimiento de relaciones de intercambio. Altamente protocolizados, podían durar horas. Facilitaban las relaciones intercomunitarias e interétnicas. En el mundo piaroa contemporáneo es sustituido por un diálogo entre anfitriones y huéspedes que, así mismo, permite ubicarse parental y espacialmente. 
surgen todos los días las voces de las ranas buré, del mono aullador y de Worá, que sugieren trabajar adentro para la fiesta, y de ella saldrán los warimes cada vez que van a visitar la maloca. El corredor despojado de la vegetación que rodea a la maloca, en nuestro caso redonda, es el escenario en el que se moverán las voces extraordinarias que visitan el recinto, luego de ser convocadas por el chamán “dueño del Warime” o Warimeruwa. Mientras los seres extraordinarios se pasean por fuera y hacen sonar sus voces, adentro son escuchados por las mujeres, los niños y algunos hombres. Estos últimos tienen la libertad para salir y entrar si así lo desean. La comunicación es unívoca y los mensajes van de los seres extraordinarios a quienes se encuentran en la maloca. El único diálogo posible, como veremos más adelante, se da entre Buoisa y las mujeres. El resto son monólogos de cada uno de los miembros de un ensamble que se escucha como un coro de voces. Se trata entonces de un escenario segregado por género y edad en el que el protagonismo corresponde a los seres extraordinarios.

El momento más sublime de la fiesta ocurre al caer la oscuridad de la primera noche, luego de que durante el día la maloca ha sido visitada por primera vez por los warimes. En ese momento, desde la profundidad de la noche y en medio de la oscuridad, con todos los fuegos apagados, la maloca es visitada por un ensamble de voces de seres extraordinarios que primero se acercan y luego dan vueltas alrededor de ella, muy cercanos a las paredes de palma. Estas voces resuenan y sobrecogen al escucha en el espacio cerrado y oscuro de la maloca donde los ecos llenan el espacio de sonidos. En el caso de la fiesta en la que participamos ${ }^{14}$, podían escucharse en polifonía la voz de Worá, intermitente y profunda, la sugestiva voz de Chuvó, los chillidos de los Buoisa y el sonido de Imu, el mono aullador, cada uno ofreciendo su propio discurso musical.

La impresión que resulta es que cada voz del ensamble tiene su propia línea melódica. Worá produce tramas que se repiten, ejecutadas por dos intérpretes que se alternan en forma secuencial, uno detrás del otro, hasta que al final cambia la rítmica antes de terminar ese segmento musical para concluir en un sonido largo. Luego se produce un silencio y se inicia un nuevo segmento siguiendo el mismo patrón. Buoisa, el escandaloso, el de los sonidos agudos, se multiplica. Son varios los buoisas presentes, quienes se distribuyen a lo largo

14 Trabajo con los piaroas desde 1984. En aquel momento solo se sabía de tres chamanes que aún hacían warimes. El evangelismo era hegemónico en tierras piaroas y el chamanismo estaba acorralado. Los pocos practicantes eran muy celosos de mostrar su fiesta. Nosotros la conocíamos por las descripciones de Agerkoop (1983), Anduze (1974) y una película de Monod. En 1988 nos dejaron participar en un Ime Warime que es el que describimos en nuestros trabajos. De esa experiencia también salió un video llamado Warime 89, que lleva la firma de Jean Chiappino (1993). 
de las paredes articulando voces y convocando a las mujeres. Imu marca la voz de los monos aulladores en un sonido zumbador que evoca los cantos de estos animales. Finalmente, tenemos la voz de Chuvó, que se expresa con una melodía ronca con variantes en la altura de la voz que le dan expresividad, masculina y seductora, como en el mito de creación de las enfermedades.

Todos ellos son familia. De Worá se dice que es la madre de todos los instrumentos. Como dueña de la agricultura ella evoca a Cheheru, la hermana menor de los demiurgos. Buoisa, por su torpeza, evoca al hermano mayor, Buoka, un demiurgo fracasado que pasa su vida tratando de hacer lo que logra su hermano menor, Wajari y, finalmente, Imu, que es hijo de Worá. Esto en cuanto corresponde al Warime observado por nosotros, pues de otros warimes se reportan otras voces producidas por flautas, como Daa, la anaconda (Eunectes murinus), y Yajó, el tucán, quienes también son hijos de Worá. Lo que tenemos, entonces, no es una orquesta sino un bullicio de miembros de una familia que anuncian su presencia y solicitan, en reciprocidad, que se los alimente y se les dé de beber. Para eso fueron invitados.

El escenario se ve completo cuando constatamos el calibre de los invitados que están presentes pero que no son necesariamente voces musicales. Worá es la dueña de los frutos y productos agrícolas; Ojuo'daa, el que tiene su barriga llena de cerveza de yuca, es el dueño de los animales del agua; Reyó, el mítico Mara Reyó, es el dueño de los animales de la tierra y el aire. Todos asisten. Cada uno representa un ámbito de la predación, pero solo el de la agricultura y la cultura es musical. Con ellos, los invitados a la fiesta están completos.

\section{Cuarto escenario: Buoisa y la sexualidad expuesta}

El más estridente de los personajes y el que emite la voz con mayor variedad de sonidos es Buoisa, el Viejo (de buo = viejo e itsa = uno/individuo). Aquí la música muy aguda generada por el instrumento se transforma en voz modulada cuando interactúa y se multiplica. Mientras los otros instrumentos son únicos, los buoisas son varios. Solo en el caso de que en la fiesta haya dos o más dueños de Warime (Warimeruwa), se podrán escuchar dos o más worás o dos o más chuvós. De resto son solo uno. Los buoisas anuncian su presencia con sonidos estridentes y convocan a las mujeres que están dentro de la maloca, al otro lado de la pared de hojas de palma, a conversar con ellos. Se trata de un viejo libidinoso que establece conversaciones banales y de quien se burlan las mujeres. Su voz intermitente pregunta insistentemente sobre la actividad sexual de las mujeres y ellas le responden, a veces convocándolo a tener relaciones sexuales con ellas, diciéndole que 
es impotente o riéndose de sus travesuras. Se trata de un diálogo canónico, en el que cada quien habla cuando le corresponde, donde no hay respeto a jerarquías ni miedo al potencial dañino del personaje. Es un diálogo transgresor donde un personaje extraordinario es tratado como alguien menor, intrascendente.

\section{Discusión}

Hemos escogido cuatro momentos de comunicación musical en el Warime para poder entender la complejidad de la función de los códigos sonoros en contextos y con personajes diferenciados. Lo primero que constatamos es que la fiesta pasa por fases en las que las voces varían tanto en la frecuencia de su presencia como en el momento en que ella ocurre. Así mismo, vemos que los personajes extraordinarios que asisten a la fiesta no son iguales (aun cuando todos sean chamanes) y que, al mismo tiempo, el rol de los chamanes piaroas tampoco lo es. No es lo mismo el tumulto de voces que se comunican cuando la familia de voces rodea la maloca, o la voz de Worá que anuncia el cumplimiento de las etapas que conducen al momento principal de la fiesta, que los diálogos de Buoisa. Tampoco es lo mismo una comunicación generada en la invisibilidad, y basada solo en lo que se escucha, que un diálogo cara a cara, como el que se da entre los warimes enmascarados y la mujer que les da la bienvenida, los alimenta y les da de beber.

El Warime solo puede ser entendido como un encuentro entre diferentes donde cada quien hace uso de sus mejores competencias para ubicarse en él. Los instrumentos musicales son, por el conjunto de restricciones que su uso implica, aquellos que están revestidos de mayor poder y peligro. Están también presididos por la figura que representa el más alto nivel cultural ${ }^{15}$ : aquel que en Worá está representado por la agricultura y por las canciones que ayudan a curar y mantener la salud de los indígenas y a prevenir la acción de otros chamanes peligrosos.

Los cantos chamánicos (meyé) que permiten a los cantadores o meyeruwa mantener prolíficos sus territorios ocurren en otros contextos. Allí, un coro de cantadores repite los versos que canta el meyeruwa principal y que tienen por fin mantener el bienestar de la comunidad. El único instrumento que se escucha es el de la maraca tradicional suramericana, con una calabaza que sirve de caja de resonancia a un grupo de semillas y piedrillas de cuarzo que funcionan como

15 Para los piaroas, cubrir con tapasexo de algodón sus órganos sexuales y practicar la agricultura son indicadores de un alto nivel cultural que contrasta con la desnudez y con la incertidumbre de la caza, la pesca y la recolección. 
un sonajero al entrechocar unas con otras. Este es un contexto donde la música desempeña otros roles asociados a la comunicación y las relaciones de mutua conveniencia con seres con quienes acuerdan el uso de los recursos de la predación. Estos cantos ocurren, con frecuencia de un día de por medio, durante un mes antes de la llegada de las máscaras. Con ellos, el Warimeruwa administra las fuerzas que han de permitirle tener una fiesta fructífera y protegida.

En la música del Warime y en sus voces musicales se representa el sector más importante de la predación: el de la agricultura, mas no es el único. Allí también está Ojuo’daa, el dueño de los animales del agua que brinda a los comensales la bebida fermentada de yuca preparada por el equipo de mujeres de la comunidad bajo la coordinación de la mujer que es su dueña (Sariruwa). Para él no hay lenguaje musical. Finalmente, también está Reyó, representando a Mará Reyó, el dueño de todos los animales del aire y la tierra. Llega como los warimes, envuelto en un traje de fibra vegetal y con una enorme máscara negriblanca, mientras porta en sus manos carnes de sus animales para el disfrute de la fiesta. Lleva un cayado que utiliza como bastón, pero también como trampa para capturar a las mujeres con quienes busca procrear. No tiene voz, no habla, ni tiene instrumentos musicales.

Vista en el contexto de la totalidad de la fiesta, la música solo ocupa un lugar destacado en los mecanismos de comunicación cuando llegan los warimes liderados por Wajari y se presentan, cuando llegan las voces de la familia de Worá y cuando Worá misma celebra el cumplimiento de cada una de las fases que permiten desarrollar el Warime hasta el final. Si Buoisa es Buoka, Worá es Cheheru y tanto Chuvó como el Warime principal son Wajari, entonces los códigos musicales son protagonistas de la gesta creadora protagonizada por los demiurgos. Ellos serían, por tanto, hálito, soplo vital, transformado en código musical.

Nos faltaría ahora intentar responder por qué los otros seres extraordinarios -Ojuo’daa y Mará Reyó- no se expresan en términos musicales. Nuestra hipótesis es que ambos son el resultado de procesos inconclusos de hominización, lo cual es evidente en el caso de Mará Reyó, una versión cultivada de los Reyó, humanoides que viven en cerros rocosos desde donde atacan a los piaroas y capturan a sus mujeres con quienes procrean. En el caso de Ojuo'daa, se trata de un personaje del río que es una mezcla de tapir (Tapirus terrestris) y la anaconda que, aunque manejaban y dieron a su nieto Wajari el conocimiento sobre el mortífero chamanismo maripa, no tenían ni música ni baile propio. Los códigos musicales parecieran ser del dominio exclusivo de seres cultivados, como los demiurgos Wajari, Buoisa y Cheheru, organizadores del primer Warime. Es, entonces, la música una obra de demiurgos cultivados al servicio de los poderes originarios de Anamain y no de seres extraordinarios. 


\section{Conclusión}

En el mundo piaroa los códigos musicales que se expresan en el Warime parecen variar atendiendo a quien los utiliza y a su función comunicativa. Ellos generan situaciones en las que la comunicación puede convertirse en diálogo, como en el caso de los mirray de presentación que consolidan imagen y dominios femeninos y masculinos, históricos y míticos. También puede ser un monólogo, como cuando Worá anuncia al entorno el logro de los fines que conducen a la fiesta, o bulliciosos polílogos, como los que se dan cuando el ensamble de voces da vueltas de noche alrededor de la maloca para hacer entender sus voces musicales. Aquí no se trata de chamanes mediando sino de seres extraordinarios convocados por el dueño de la fiesta que llegan a ella expresándose con el lenguaje que cada uno maneja. No se trata de mediación, como cuando el rezador invoca a los seres del mundo en general y de las montañas sagradas para promover la fertilidad del entorno o para purificar las carnes de cacería, sino de presencia. No es por tanto un código musical que solo regula la intermediación entre los hombres y los seres extraordinarios, sino también códigos musicales que transportan información y permiten la relación directa entre los humanos y sus invitados extraordinarios. Finalmente, entendemos que la música y los códigos que emergen de ella son la expresión más cultivada del principio vital del hálito, soplo que resulta del acto mismo de respirar, y que en el encuentro entre la música y el canto encuentra su expresión más sofisticada. En definitiva, es un acto de reafirmación de calidad cultural frente a la incompletitud o la barbarie de otros.

\section{Referencias}

Agerkoop, Terry. 1983. Piaroa, Venezuela. Caracas: Inidef.

Anduze, Pablo. 1974. Dearuwa: los dueños de la selva, vol. XVIII. Caracas: Biblioteca de la Academia de Ciencias Físicas, Matemáticas y Naturales.

Arnhem, Kaj. 1981. Makuna Social Organization. A Study in Descent, Alliance and the Formation of Corporate Groups in the North-Western Amazon. Serie: Acta Universitatis Upsaliensis (libro 4). Uppsala: Almqvist \& Wiksell International. https://doi.org/10.2307/2801726

Boglar, Lajos. 1971. “Chieftainship and the Religious Leader: A Venezuelan Example”. Acta Ethnographica 20 (3-4): 331-337.

-. 1976. “Creative Process in Ritual Art: Venezuela”. En The Realm of the Extrahuman, editado por Agehanada Bharati, 347-353. La Haya: Mouton Publishers. 
—. 1999. "Warime: el poder de las máscaras". En Orinoco-Parima. Comunidades indígenas de Venezuela, editado por Juan Luis Delmont, 162-187. Colección Cisneros. Ostfildem-Ruit: Hatje Cantz Verlag.

Brabec de Mori, Bernd, Matthias Lewy y Miguel A. García, eds. 2017. Sudamérica y sus mundos audibles. Cosmologías y prácticas sonoras de los pueblos indígenas. Berlín: IberoAmerikanisches Institut PreuBischer Kulturbesitz.

Chiappino, Jean. 1993. Warime 89. Fete des masques dans une communauté Wotjuja. Documento audiovisual. París: IRD.

De la Hoz, Nelsa. 2015. "Ukuo and Tabotu between the Piaroa of the Mataven Rainforest in the Colombian Orinoquia". Tipiti, Journal of the Society for the Anthropology of Lowland South América 13 (2): 151-161. http://digitalcommons.trinity.edu/tipiti/vol13/iss2/11

Del Rey Fajardo, José (S. J.). 2010. “El ‘mirray’ o la cultura del contacto en los llanos colombovenezolanos”. Cuadernos Unimetanos 21: 4-8.

Gheerbrant, Alain. 1953. L’Expedition Orénoque-Amazone. París: Gallimard.

Goldman, Irving. 1948. "Tribes of the Vaupés-Caquetá Region”. En Handbook of South American Indians, vol. III, editado por Julian Steward, 763-798. Washington: Smithsonian Institute.

González, Omar. 1986. "Sexualidad y rituales de iniciación entre los indígenas warekena del río Guainía-Río Negro. TFA”. Montalbán 17: 103-138.

Goulard, Jean Pierre y Dimitri Karadimas, eds. 2011. Masques des hommes, visages des dieux. París: CNRS Editions.

Gumilla, Joseph. 1988. El Orinoco ilustrado y defendido, historia natural, civil, y geographica de este gran rio, y de sus caudalosas vertientes. Gobierno, usos, y costumbres de los indios sus habitadores, con nuevas y útiles noticias de Animales, Arboles, Frutos, Aceytes, Yervas y Raices Medicinales; y fobre todo fe hallaran converfiones muy fingulares a N. Santa Féy cafos de mucha edificación. Valencia: Generalitat Valenciana.

Hill, Jonathan. 1993. Keepers of the Sacred Chants: The Poetics of Ritual Power in an Amazonian Society. Tucson: University of Arizona Press.

Hill, Jonathan D. y Jean Pierre Chaumeil, eds. 2011. Burst of Breath. Indigenous Ritual Wind Instruments in Lowland South America. Lincoln. Londres: University of Nebraska Press.

Hugh-Jones, Stephen. 1979. The Palm and the Pleiades. Cambridge: Cambridge University Press.

Jackson, Jean. 1983. The Fish People. Linguistic, Exogamy and Tukanoan Identity in Northwest Amazonia. Cambridge: Cambridge University Press.

Lowie, Robert. 1948. "The Tropical Forests. An Introduction”. En Handbook of South American Indians, vol. III, editado por Julian Steward, 1-56. Washington: Smithsonian Institute.

Mansutti, Alexander. 1990. Los piaroa y su territorio. Caracas: Cuadernos de Trabajo del Ceviap.

—. 2002. "Le parcours des créatures de Wajari: socialisation du milieu naturel, système régional et migrations chez les Piaroa du Venezuela”. Tesis doctoral en Antropología y Etnología, Ehess, París. 
-. 2003. "Recreación de la ancestralidad y actualización de la recreación: la representación fecundadora y el Warime”. Ponencia presentada en el Seminario Image, Performance and Representation in Shamanistic American Societies, St. Andrews University, Escocia, 30 de enero al 2 de febrero.

-. 2006. Warime: la fiesta. Flautas, trompas y poder en el Orinoco. Ciudad Guayana: Fondo Editorial UNEG.

-. 2011a. "Flutes in the Warime: Musical Voices in the Piaroa World". En Burst of Breath. Indigenous Ritual Wind Instruments in Lowland South America, editado por Jonathan D. Hill y Jean Pierre Chaumeil: 147-170. Lincoln; Londres: University of Nebraska Press.

-. 2011b. "Les masques des pouvoirs: le warime piaroa”. En Masques des hommes, visages des dieux, editado por Jean-Pierre Goulard y Dimitri Karadimas: 155-181. París: CNRS Editions.

—. 2012. "Yuruparí: máscaras y poder entre los piaroas del Orinoco". Espaco Ameríndio 6: 46-75.

Mansutti, Alexander y Noël Bonneuil. 1994-1996. "Dispersión y asentamiento interfluvial llanero: dos razones de sobrevivencia étnica en el Orinoco Medio del post-contacto". Antropológica 84: 43-71.

Metraux, Alfred. 1982. Les indiens de l'Amérique du Sud. París: Editions A. M. Métailié.

Monod, Jean. 1970. "Los piaroa y lo invisible: ejercicio preliminar de un estudio sobre la religión piaroa”. Boletín Informativo de Antropología VII: 5-21.

—. 1972. Un riche cannibale. París: Union Generale d’Editions.

—. 1987. Worá, la deesse cachée. París: Les Éditeurs Évidant.

Oldham, Paul. 1996. "The Impacts of Development and Indigenous Responses among the Piaroa of the Venezuelan Amazon”. Tesis doctoral en Antropología Social, London School of Economics and Political Science, Londres.

Overing, Joanna. 1975. The Piaroa: A People of the Orinoco Basin. A Study on Kinship and Marriage. Oxford: Clarendon Press.

Pérez, Antonio. 1988. "Los balé (baré)”. En Los aborígenes de Venezuela, vol. III, editado por Jacques Lizot, 413-478. Caracas: Fundación La Salle; Monte Ávila.

Reichel-Dolmatoff, Gerardo. 1973. Desana. Le symbolisme universel des indiens tukano du Vaupés. París: Gallimard.

-. 1996. Yuruparí. Studies of an Amazonian Foundation Myth. Cambridge: University of Cambridge Press.

Vidal, Silvia. 2002. "Secret Religious Cults and Political Leadership: Multiethnic Confederacies from Northwestern Amazonia”. En Comparative Arawakan History: Rethinking Language Family and Culture Area in Amazonia, editado por Jonathan D. Hill y Fernando Santos Granero, 248-268. Chicago; Urbana: University of Illinois Press.

Wavrin, Marqués de. 1948. Les indiens sauvages de l’Amérique du Sud. Vie sociale. París: Payot.

Wilbert, Johannes. 1966. Indios de la región Orinoco-Ventuari. Caracas: Fundación La Salle de Ciencias Naturales. 
Wright, Robin. 1998. Cosmos, Self and History in Baniwa Religion. For those Unborn. Austin: University of Texas Press.

-. 2002. "Prophetic Traditions among the Baniwa and other Arawakan Peoples of the Northwest Amazon”. En Jonathan D. Hill y Fernando Santos Granero, 269-293.

Zent, Stanford. 1992. "Historical and Ethnographic Ecology of the Upper Cuao River Wothiha: Clues for an Interpretation of Native Guianese Social Organization”. Tesis doctoral en Antropología, Graduate School of Arts and Sciences, Columbia University, Nueva York. 